\title{
Unreceptivity - a phenomenon induced by male accessory gland secretions in female Helicoverpa armigera
}

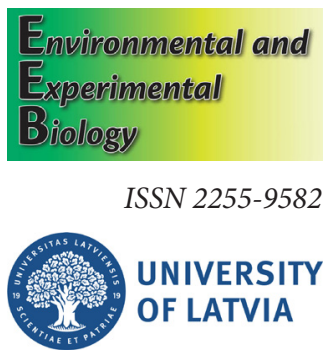

\author{
Rama Thyloor ${ }^{1}$, Tannavi Kiran², Doddamane Manjulakumari²* \\ ${ }^{1}$ Department of Biotechnology, Government Science College, Bengaluru, 560 001, India \\ ${ }^{2}$ Department of Microbiology and Biotechnology, Bangalore University, Bengaluru, 560 056, India \\ ${ }^{\star}$ Corresponding author, E-mail: manjulakumari_doddamane@yahoo.co.in
}

\begin{abstract}
Unreceptivity, a phenomenon generally observed in female insects following mating, was investigated by simulating a mating situation in Helicoverpa armigera females by injecting male accessory glands and duplex (MAG-duplex) extracts sans sperm. Injection of extracts into the abdomen of virgin females induced unreceptivity. The virgin females started behaving like mated females by rejecting the males by avoiding the advances made by the latter to mate. Unreceptivity was observed in about $93 \%$ of the females on the day of injection, which reduced to $82 \%$ on the second scotophase compared to controls. However, on the third day, $75 \%$ of them reverted back to receptivity that was comparable to virgin count. The Tricine-SDS-PAGE of MAG-duplex of virgin and mated male moths revealed the conspicuous absence of a low molecular weight $(<7 \mathrm{kDa})$ peptide band in the mated moths, and the possibility of being delivered to female at the time of mating. MALDI-TOF spectra of the same extracts showed the presence of several peptides $<7 \mathrm{kDa}$, further, the absence of them in mated moths.
\end{abstract}

Key words: Helicoverpa armigera, male accessory gland, peptide, unreceptivity.

Abbreviations: CA, corpora allata; JH, juvenile hormone; MAG, male accessory gland; PBAN, pheromone biosynthesis activating neuropeptide; PBS, phosphate buffered saline; SP, sex peptide.

\section{Introduction}

Studies over the past six decades have shown that in many insect species, mating profoundly influences the female to remodel her reproductive behaviour and physiology as a consequence of altered gene expression, in turn influenced by male origin factors. These changes trigger responses in several processes that lead to the production of progeny. In many insect females, mating elicits a series of well-defined behavioural changes (Gillott 1988). Among the most conspicuous are (1) an increase in egg-laying rate and (2) the reduction of receptivity (Wolfner 1997; Gillott 2003), the earlier, to the advantage of female and the latter to the advantage of male. These changes in female reproductive behaviour are induced by substances synthesized in the tissues of the male reproductive system and transferred as part of the seminal fluid to the female during copulation (Kubli 1996). Numerous studies have demonstrated that the male accessory glands are the key secretory structures contributing to the seminal fluid that plays an essential role in insect reproduction. Their main function is the production of the spermatophore for sperm transfer from male to female; changes in the behaviour of females are also attributed to the peptides/proteins present in their secretion.
In most moth species, females attract males by releasing pheromones during a characteristic 'calling' phase, to which males respond through courtship behaviour followed by females reciprocating, which ensues in mating. However, a once mated female does not respond to the males' courtship behaviour. In species in which females exhibit multiple mating and sperm competition exists, there is a period of unreceptivity following mating (Chen 1984; Gillott 1988; Eberhard 1996). A strategy evolved to inhibit multiple mating by first mating males is the reason behind the reduced receptivity of the females (Simmons 2001). The unreceptivity of such females of many insects is caused by components of seminal fluids, and/or the sperm itself, and possibly by mechanical stimulation (Manning 1962; Manning 1967; Gromko et al. 1984; Letsinger, Gromko 1985; Scott 1987; Eberhard 1996; Miyatake et al. 1999; Simmons 2001). This unreceptivity, defined as non-mating status, may be seen as an active rejection of would-be mates (refractoriness) or as a passive decline in attractiveness. Actually, some insect females likely remate after egg-laying, but not those who are in the active period of egg laying (Fox, Hickman 1994; Harano et al. 2006b), in other words an unreceptive or non-mating status indicating deposition of a certain quota of eggs is essential for her to regain receptivity. 
Helicoverpa armigera (Lepidoptera: Noctuidae), being polyphagous, poses a problem for several agriculturally important crops across the continents. Many strategies of pest control to curb this insect, from chemical pesticides to Bt technology, have failed (Armes et al. 1996; Heckel et al. 2007). A deep understanding of the insects' behaviour and physiology may help in developing alternative strategies, such as disruption of mating and or oviposition to check the population.

\section{Materials and methods}

\section{Insects and culture}

A starter culture of neonates of $H$. armigera (NBAIIMP-NOC-01) was procured from NBAIR, Bengaluru, and reared on a modified semi-synthetic chickpea diet developed by Shobha et al. (2009). The $3^{\text {rd }}$ instar larvae were maintained individually in a plastic cup at $25^{\circ} \mathrm{C}, 65 \pm 5 \%$ relative humidity and $16 \mathrm{~h}$ light $/ 8 \mathrm{~h}$ dark conditions in a BOD incubator. Pupae were collected and sexed according to the characteristics of their exterior paramera. The male and female pupae were kept separately in plastic boxes until adult emergence to ensure virginity and age. Unless stated otherwise, all female adults used in this study were 2-dayold (used for experiments in the second scotophase after eclosion).

\section{Preparation of male accessory gland-duplex extract}

Adult virgin males from $2-6$ days after emergence were dissected using ice-cold lepidopteran saline (Bindokas, Adams 1988), and the whole reproductive system was transferred into a clean sterilized petri plate. The male accessory gland (MAG) duplex was collected in microcentrifuge tubes $(1.5 \mathrm{~mL})$ and kept at $-40{ }^{\circ} \mathrm{C}$. The dissections were carried out after two hours of onset of scotophase.

Tissues pooled from 300 moths were homogenized using an IKA tissue homogenizer in 20 fold excess (w/v) of Bennett's extraction buffer (Bennett 1978) and centrifuged at $15000 \mathrm{~g}$ for $20 \mathrm{~min}$ at $4{ }^{\circ} \mathrm{C}$, and the supernatant was collected carefully without fat. The pellet was similarly extracted two times with buffer. All of the three supernatants were pooled, desalted using a C18 Sep-Pak cartridge (Waters, USA) as described by Kingan et al. (1993), freeze dried and stored at $-40{ }^{\circ} \mathrm{C}$ until use. For bioassays the lyophilized extract was dissolved in $900 \mu \mathrm{L}$ of phosphate buffered saline.

\section{Preparation of MAG-duplex extract for Tricine-SDS-PAGE and MALDI-TOF}

Virgin and mated males of the second scotophase were dissected using ice-cold lepidopteran saline and MAGduplex tissue was collected from ten virgin and mated males in vials placed on ice. The tissue was homogenized using Milli-Q water ( $20 \mu \mathrm{L}$ per moth) with a micro pestle
(Tarson) and centrifuged at $12000 \times \mathrm{g}$ for $15 \mathrm{~min}$ at $4{ }^{\circ} \mathrm{C}$. The supernatant was collected carefully without fat and stored at $-40{ }^{\circ} \mathrm{C}$.

\section{Tricine-SDS-PAGE electrophoresis}

Proteins were separated by one-dimensional Tricine-SDSPAGE electrophoresis with Tricine-Tris buffer systems. Resolving (16\%), spacer (10\%) and stacking (4\%) gels were prepared (Schägger 2006). Samples $(20 \mu \mathrm{L})$ from virgin and mated males were mixed with $4 \mathrm{X}$ sample buffer (12\% SDS, 30\% glycerol, $0.05 \%$ Coomassie Brilliant Blue G-250, $150 \mathrm{mM}$ Tris/HCl, $\mathrm{pH}$ 7.0) and were loaded on the gel. The proteins/peptides bands were visualized by staining the gel with Coomassie Brilliant Blue R-250 (SRL, India) after placing the gel in fixing solution (50\% methanol, $10 \%$ acetic acid, and $100 \mathrm{mM}$ ammonium acetate). The molecular weights of the bands were determined by comparison with the electrophoretic mobilities of a series of low-range protein standards (SRL, BioLit).

\section{MALDI-TOF analysis}

The MAG-duplex crude aqueous extract of 2-day-old virgin and mated males was submitted for MALDI-TOF analysis (ultra fleXtreme, Bruker Daltonics, Germany) at IISc, Bengaluru, India. The mass spectra were acquired using a Flex control (Bruker) and analysis was done using Flex Analysis 3.1 (Bruker) software, with a smart beam laser $(2 \mathrm{~Hz})$.

\section{Effect of MAG-duplex extract}

To study how MAG-duplex secretions influenced female mating receptivity, we set up four treatments: (i) virgin females injected with MAG-duplex extract (28), (ii) virgin females injected with phosphate buffered saline (PBS) (30), (iii) virgin females (35), and (iv) virgin female mated with a naive males ( 2 to 6 day old) in the ratio 1:5, the male was removed after mating (25). Injections for the treatments were done at the beginning of the second scotophase after emergence. The females were cold anesthetized, prior to injection, by exposing them to a temperature of $4{ }^{\circ} \mathrm{C}$ for 5 $\mathrm{min}$. These insects were placed on an ice tray and injected $3 \mu \mathrm{L}$ (one male equivalent) of MAG-duplex extract using a Hamilton syringe into the abdominal cavity through a intersegment membrane (Jin, Gong 2001). Females were allowed to recover for $15 \mathrm{~min}$ at $4{ }^{\circ} \mathrm{C}$ after injection. For treatment 4 , matings were allowed by pairing the insects at the beginning of the second scotophase after emergence and males were removed immediately after mating. The females who were mated for $1 \mathrm{~h}$ were selected for bioassay. The experimental female moths were kept individually in a transparent plastic cup $(8.5 \times 6.5 \mathrm{~cm})$ and cotton wads soaked in $10 \%$ honey were provided as food. Illumination during observation was provided by a $30 \mathrm{~W}$ red light.

After treatment female receptivity was recorded quickly by scanning all treated moths every $15 \mathrm{~min}$ and observing 

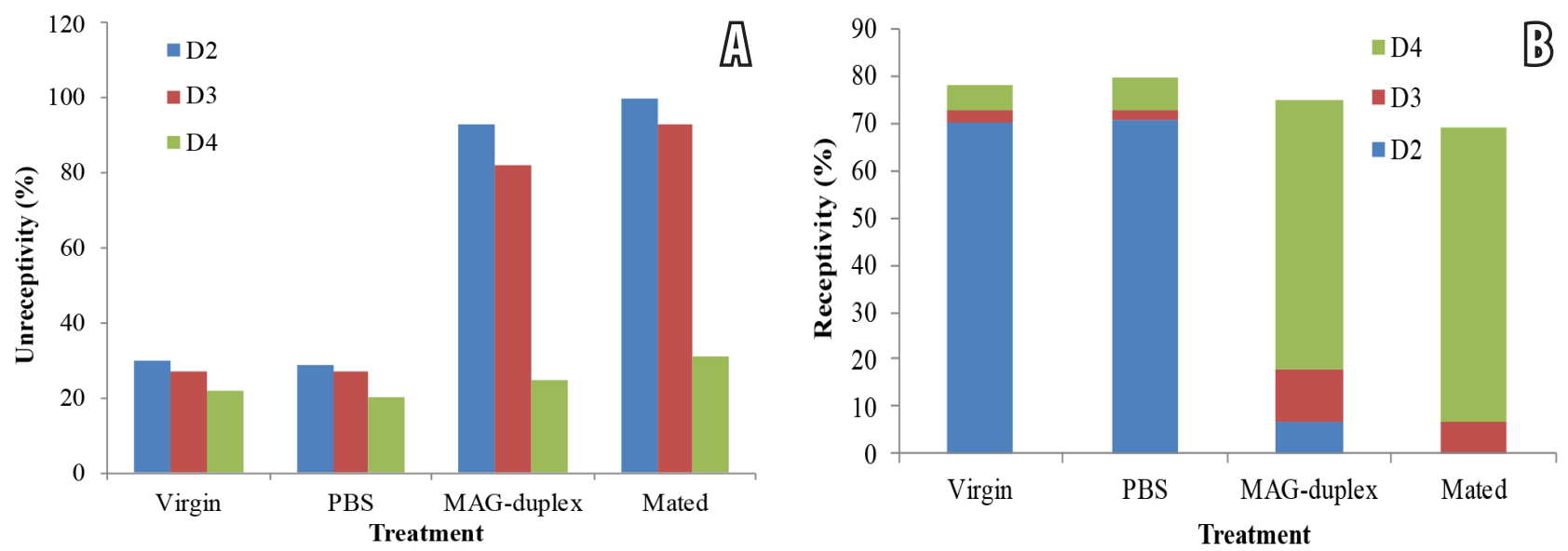

Fig. 1. A, effect of MAG-duplex extract on unreceptivity in comparison with phosphate buffered saline (PBS) injected (control), virgin and mated. B, Receptivity in moths injected with MAG-duplex extract in comparison with virgin, mated and PBS (control) injected females. D2, second day; D3, third day; D4, fourth day.

the extrusion of the ovipositor to the outside (Raina et al. 2000).

\section{Statistics}

$\chi^{2}$-tests were used for comparison between two treatments. For a comparison among more than three treatments, sequential Bonferroni methods (Rice 1989) were applied after the $\chi^{2}$-test at the $1 \%$ significance level. $\mathrm{R}$ version 3.0.2 software was used for $\chi^{2}$-tests.

\section{Results}

\section{Effect of MAG-duplex secretions on female mating receptivity}

Injection of MAG-duplex extracts into the abdomen of virgin females inhibited receptivity. The injected females spurned the males that made advances to mate. The rejection to mate was observed in about $93 \%\left(\chi^{2}=20.571, d f\right.$ $=1, p<0.01)$ of the injected females on the day of injection, which reduced to $82 \%\left(\chi^{2}=11.571, d f=1, p<0.01\right)$ on the second day and was less than $25 \%$ on the third day, an indication that $75 \%$ of them reverted back to receptivity.

A similar trend was observed in mated female moths with $100 \%\left(\chi^{2}=25, d f=1, p<0.01\right)$ rejection on the day they mated. Unreceptivity reduced on the second day by 93\% $\left(\chi^{2}=20.571, d f=1, p<0.01\right)$ and $31 \%$ on the third day, with a reversion of $69 \%$ to receptivity. Virgins and PBS injected females showed only $29 \%$ and $30 \%$ rejection, respectively, on the day of treatment $\left(\chi^{2}=6.428, d f=1, p\right.$ $>0.01$ ), which further decreased to $27 \%$ (in both cases) on the second $\left(\chi^{2}=6.533, d f=1, p>0.01\right)$ and $22 \%$ and $20 \%$ on third day, respectively. The unreceptivity induced in mated females was temporary and lasted for two days similarly in injected moths, whereas virgins and PBS injected females were highly receptive on the day of the treatment itself (Fig. $1)$.

\section{Protein profile of MAG-duplex of virgin and mated male moths by Tricine-SDS-PAGE}

The protein profile of MAG-duplex of male moths before and after mating showed the presence of single band $<7$ $\mathrm{kDa}$ in virgin male moths, which was absent in the mated moths (Fig. 2), suggesting the possibility of that protein being transferred along with the sperm to the female at the time of mating.

\section{MALDI-TOF analysis of MAG-duplex extract of virgin and mated male moths}

MALDI-TOF spectra of the MAG- duplex of virgin and

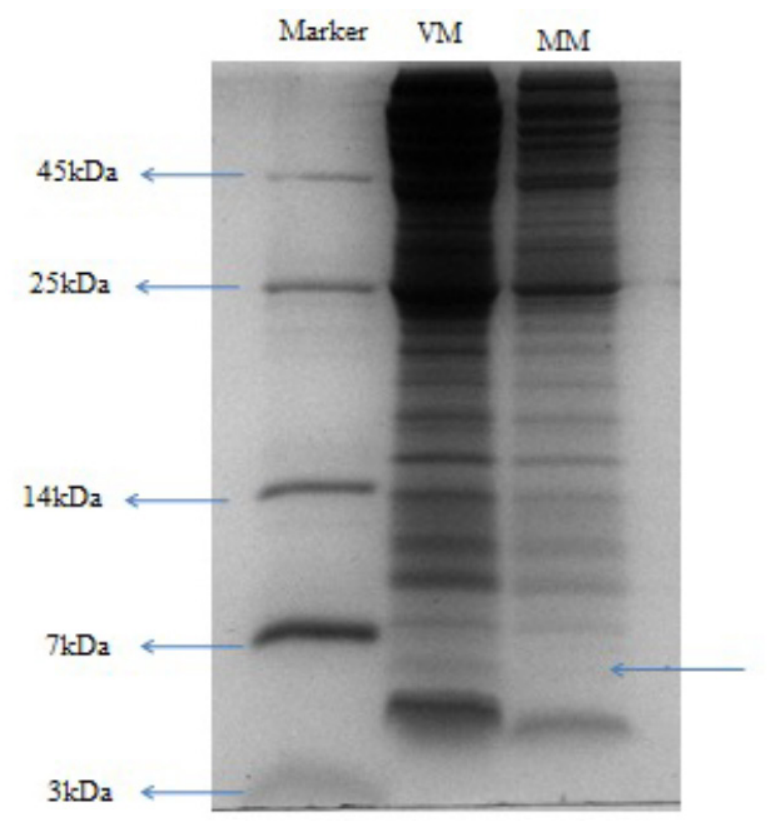

Fig. 2. Tricine-SDS-PAGE of MAG-duplex extract showing the disappearance of a protein $<7 \mathrm{kDa}$ in mated males. $\mathrm{VM}$, virgin male; MM, mated male. 


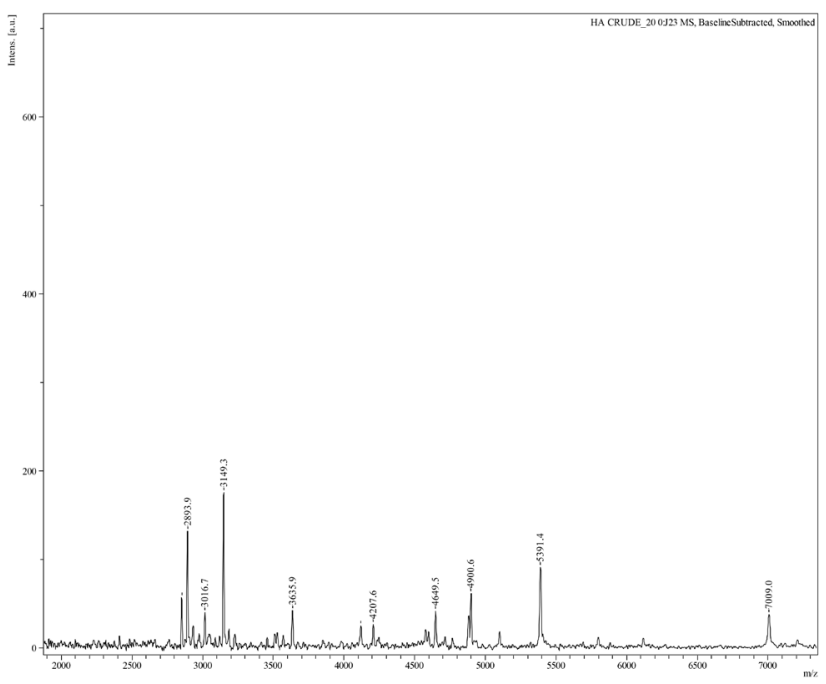

Fig. 3. MALDI-TOF spectrum of MAG-duplex extract of virgin males showing the presence of proteins ranging between 3 and $7 \mathrm{kDa}$.

mated moths showed the presence of several peptides < $7 \mathrm{kDa}$ in virgin male moths, all of which were absent in the mated moths, further confirming the results of PAGE analysis. However, contrary to a single band of $<7 \mathrm{kDa}$ on the PAGE, MALDI-TOF spectra revealed the presence of about six peptides that were missing in the mated moth spectra (Fig. $3 \& 4$ ).

\section{Discussion}

The present study showed that the male accessory gland secretions were able to induce unreceptivity. Duplex was also pooled with accessory glands to ensure the maximum harvest of secretions that were collected and stored for a brief period in them. The modulation of physiology in the female was evident, as more than $90 \%$ of injected female moths were unreceptive to the male moths' advances. It was also evident that uneceptivity was temporary, as they resumed receptivity on the third day to mate; as many as $75 \%$ of the injected moths mated on that day. The pause period was about $48 \mathrm{~h}$, during which they were actively laying eggs. It is possibile that the female will be ready to mate, in turn, receiving sperm, once all fertilized eggs are laid.

The male factors induce termination of female receptivity due to loss in pheromone production (Raina 1989). Further study on neuroendocrine regulation of pheromone biosynthesis in moths to unravel the mechanism of termination of receptivity has been carried out (Rafaeli 2001). It seems that the male accessory gland proteins delivered to a female inactivates the Pheromone Biosynthesis Activating Neuropeptide (PBAN), thereby inhibiting the biosynthesis of pheromone, ensuing in cessation of calling for a period, which is also a possible explanation for inhibition of receptivity in $H$. armigera.

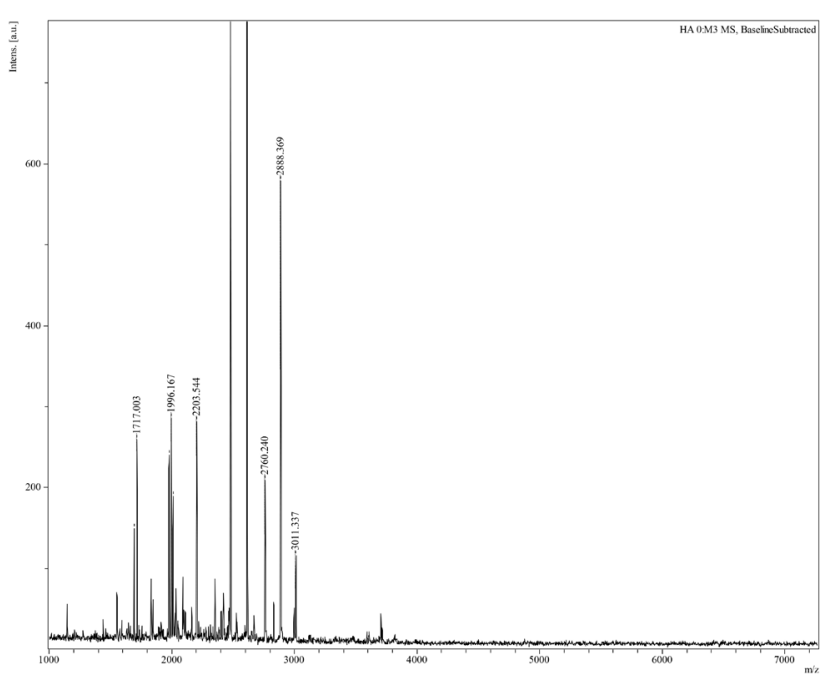

Fig. 4. MALDI-TOF spectrum of MAG-duplex extract of mated males showing the absence of proteins ranging between 3 and 7 $\mathrm{kDa}$.

Although the mechanism is unclear, several studies have shown the involvement of male accessory gland proteins in inhibition of receptivity in female insects (Raina 1989), Heliothis virescens (Ramaswamy et al. 1996), Lymantria dispar (Giebultowicz et al. 1991), Argyrotaenia velutiana (Jurenka et al. 1993), Epiphyas postvittana (Foster 1993), Bombyx mori (Ando et al. 1996), Choristoneura fumiferana and Choristoneura rosaceana (Delisle, Simard 2002).

More than one mechanism may be involved in producing the effects of male-derived substances on female receptivity. Receptivity in females is intimately associated with egg maturation at the onset of reproduction. In virgin females, egg maturation is controlled by juvenile hormone $(\mathrm{JH})$, and in turn synthesis and release of $\mathrm{JH}$ is stimulated by the corpora allata (CA) and various neuropeptides produced by the central nervous system. The work carried out on armyworm moth, Pseudaletia unipuncta, suggests that $\mathrm{JH}$ controls the release of PBAN in moths (Cusson, McNeil 1989; McNeil et al. 1996). A similar role for JH in the black cutworm, Agrotis ipsilon, was proposed (Picimbon et al. 1995). Since JH is crucial to female receptivity and since neuropeptides control $\mathrm{JH}$ production, they are central in regulating female reproduction.

It was hypothesized that a physiologically active SPlike factor, at least functionally similar to the Drosophila melanogaster sex peptide (SP), probably exists in H. armigera male moths and is transmitted to females during copulation (Fan et al. 1999; Fan et al. 2000; Nagalakshmi et al. 2004). This SP-like factor would directly inhibit pheromone biosynthesis, which is induced during the scotophase by PBAN. It would also stimulate the production of JH by the CA. The relationship between pheromone production and $\mathrm{JH}$ production in moths is yet unclear. $\mathrm{JH}$, stimulated by SP, may stimulate oviposition or exhibit other functions. It was demonstrated that a partial sequence of synthetic 
pheromonostatic peptide of Helicoverpa zea (HezPSP) could inhibit pheromone synthesis (Eliyahu et al. 2003). The work of these two researchers suggests that both SPlike and PSP-like factors may be present in the accessory glands of $H$. armigera males.

The conspicuous missing of a peptide $<7 \mathrm{kDa}$ in mated males in our study indicates the probability of being transferred to female during mating along with sperm and possibly inhibiting the receptivity in females. The studies carried on several taxonomic insect groups show that the male origin proteins responsible for inhibiting receptivity or remating are simple and small peptides with fewer than 100 amino acids (Gillott 2003) tracked to accessory glands. Ablation experiments, injection of tissue homogenates, or injection of purified components showed that the MAGs generally produce receptivity inhibiting substance and are peptide/proteins (Gillott, Friedel 1977). A 27 amino acid residue peptide in Drosophila funebris was reported (Baumann et al. 1975), while a sex peptide (Acp70A) containing 36 amino acids was characterized (Chen et al. (1988). DUP99B, a glycosylated, 31 amino acid peptide of $4932 \mathrm{Da}$ was isolated and characterized from Drosophila melanogaster male duplex (Saudan et al. 2002). A peptide of 41 amino acids with a molecular weight of $5100 \mathrm{Da}$ in Drosophila suzuki was characterized (Schmidt et al. 1993), which was responsible for inhibition of receptivity in flies. A peptide with 57 amino acids in Helicoverpa zea moths was also characterized (Kingan et al. 1995).

Several studies provide evidence of peptides of different species of same genera sharing sequence similarity with similar functions. Thus, female mosquitoes of related species shared a common reaction, reduction on mating receptivity to a component of extracts of the male accessory gland (Craig 1967). A high similarity in cDNA sequences of male sex peptides has been found in subgroups of $D$. melanogaster, including Drosophila sechellia, Drosophila simulans, and Drosophila mauritiana. Similarities in structure and physiological function of sex peptides of D. suzuki and D. melanogaster were found (Schmidt et al. 1993). These results strongly indicated that endogenous $H$. armigera proteins present in the male reproductive tract were responsible for stimulating suppression of female receptivity and the reports showed that male substances of closely related species had similar effects of reducing female mating receptivity. The above reports make us strongly believe that our peptide may exhibit similar action as HezPSP, as injected females failed to exhibit calling and in turn mating.

\section{Acknowledgements}

We thank the NBAIR, Bengaluru, for providing insect culture and MBU unit, IISc, Bengaluru, India, for extending Mass spectroscopy facilities. Sincere thanks to Mr. Sadiq Pasha for helping us in statistical analysis.

\section{References}

Ando T., Kasuga K., Yajima Y., Kataoka H., Suzuki A. 1996. Termination of sex pheromone production in mated females of the silkworm moth. Arch. Insect Biochem. Physiol. 31: 207218.

Armes N.J., Jadhav D.R., DeSouza K.R. 1996. A survey of insecticide resistance in Helicoverpa armigera in the Indian subcontinent. Bull. Entomol. Res. 86: 499-514.

Baumann H., Wilson K.J., Chen P.S., Humbel, R.E. 1975. The amino acid sequence of a peptide (PS-1) from Drosophila funebris: a paragonial peptide from males which reduces the receptivity of the female. Eur. J. Biochem. 52: 521-529.

Bennett H.P.J., Hudson A.M., Kelly L., McMartin C., Purdon G.E. 1978. A rapid method, using octadecasilyl-silica, for the extraction of certain peptides from tissues. Biochem. J. 175: 1139-1141.

Bindokas V.P., Adams M.E. 1988. Hemolymph composition of the tobacco budworm, Heliothis virescens $\mathrm{F}$. (Lepidoptera:Noctuidae). Comp. Biochem. Physiol. 90: 151155.

Chen P.S. 1984. The functional morphology and biochemistry of insect male accessory glands and their secretions. Annu. Rev. Entomol. 29: 233-255.

Chen P.S., Stumm-Zollinger E., Aigaki T., Balmer J., Bienz, M., Bohlen P. 1988. A male accessory gland peptide that regulates reproductive behavior of female D. melanogaster. Cell 54: 291-298.

Craig G.B. 1967. Mosquitoes female monogamy induced by male accessory gland substance. Science 156: 1499-1501.

Cusson M., Mcneil J.N. 1989. Involvement of juvenile hormone in the regulation of pheromone release activities in a moth. Science 243: 210-212.

Delisle J., Simard J. 2002. Factors involved in the post-copulatory neural inhibition of pheromone production in Choristoneura fumiferana and C. rosaceana females. J. Insect Physiol. 48: $181-188$.

Eberhard W.G. 1996. Female Control: Sexual Selection by Cryptic Female Choice. Princeton University Press, Princeton.

Eliyahu D., Nagalakshmi V., Kubli E., Choffat Y., Applebaum S.W., Rafaeli A. 2003. Inhibition of pheromone biosynthesis in Helicoverpa armigera by pheromonostatic peptides. J. Insect Physiol. 49: 569-574.

Fan Y., Rafaeli A., Gileadi C., Kubli E., Applebaum S.W. 1999. Drosophila melanogaster sex peptide stimulates juvenile hormone synthesis and depresses sex pheromone production in Helicoverpa armigera. J. Insect Physiol. 45: 127-133.

Fan Y., Rafaeli A., Moshitzky P., Kubli E., Choffat Y., Applebaum S.W. 2000. Common functional elements of Drosophila melanogaster sex peptide stimulates juvenile hormone biosynthesis and depresses sex pheromone production in Helicoverpa armigera. Insect Biochem. Mol. Biol. 30: 805-812.

Foster S.P. 1993. Neural inactivation of sex pheromone production in mated light brown apple moths, Epiphyas postvittana (Walker). J. Insect Physiol. 39: 267-273.

Fox C.W., Hickman D.L. 1994. Influence of oviposition substrate on female receptivity to multiple mating in Callosobruchus maculatus (Coleoptera: Bruchidae). Ann. Entomol. Soc. Am. 87: 395-398.

Giebultowicz J.M., Raina A.K., Uebel E.C., Ridgway R.L. 1991. Two-step regulation of sex-pheromone decline in mated 
gypsy moth females. Arch. Insect Biochem. Physiol. 16: 95-105.

Gillot C., Friedel T. 1977. Fecundity-enhancing and receptivityinhibiting substances produced by male insects: A review. Adv. Invertebr. Reprod. 1: 199-218.

Gillott C. 1988. Arthropoda-Insecta. In: Adiyodi K.G., Adiyodi R.G. (eds.) Reproductive Biology of Invertebrates. Wiley Press, New York, pp. 319-471.

Gillott C. 2003. Male accessory gland secretions: modulators of female reproductive physiology and behaviour. Annu. Rev. Entomol. 48: 163-184.

Gromko M.H., Newport M.E.A., Kortier M.G. 1984. Sperm dependence of female receptivity in Drosophila melanogaster. Evolution 38: 1273-1282.

Harano T., Fujisawa M., Miyatake T. 2006b. Effect of oviposition substrate on female remating in Callosobruchus chinensis (Coleoptera: Bruchidae). Appl. Entomol. Zool. 41: 569-572.

Heckel D.G., Gahan L.J., Baxter S.W., Zhao J.Z., Shelton A.M. 2007. The diversity of Bt resistance genes in species of Lepidoptera. J. Invertebr. Pathol. 95: 192-97.

Jin Z.Y., Gong H. 2001. Male accessory gland derived factors can stimulate oogenesis and enhance oviposition in Helicoverpa armigera (Lepidoptera: Noctuidae). Arch. Insect Biochem. Physiol. 46: 175-185.

Jurenka R.A., Fabrias G., Ramaswamy S., Roelofs W.L. 1993. Control of pheromone biosynthesis in mated redbanded leafroller moths. Arch. Insect Biochem. Physiol. 24: 129-137.

Kingan T.G., Thomas-Laemont P.A., Raina A.K. 1993. Male accessory gland factors elicit change from "virgin" to "mated" behaviour in the female corn earworm moth Helicovepra zea. J. Exp. Biol. 183: 61-76.

Kingan T.G., Bodnar W.M., Raina A.K., Shabanowitz J., Hunt D.F. 1995. The loss of female sex pheromone after mating in the corn earworm moth Helicoverpa zea: identification of a male pheromonostatic peptide. Proc. Natl. Acad. Sci. USA 92: 5082-5086.

Kubli E. 1996. The Drosophila sex-peptide: a peptide pheromone involved in reproduction. Adv. Dev. Biochem. 4: 99-128.

Letsinger J.T., Gromko M.H. 1985. The role of sperm numbers in sperm competition and female remating in Drosophila melanogaster. Genetica 66: 195-202.

Manning A. 1962. A sperm factor affecting the receptivity of Drosophila melanogaster females. Nature 194: 252-253.

Manning A. 1967. The control of sexual receptivity in female Drosophila. Anim. Behav. 15: 239-250.

Mcneil J.M., Laforge M., Bedard C., Cusson M. 1996. Juvenile hormone production and sexual maturation in true armyworm, Pseudaletia unipuncta (HAW) (Lepidoptera: Noctuidae): a comparison of migratory and non-migratory populations. Arch. Insect Biochem. Physiol. 32: 575-584.
Miyatake T., Chapman T., Partridge L. 1999. Mating-induced inhibition of remating in female Mediterranean fruit flies Ceratiti scapitata. J. Insect Physiol. 45: 1021-28.

Nagalakshmi V.D., Applebaum S.W., Kubli E., Choffat Y., Rafaeli. A. 2004. The presence of Drosophila melanogaster sex peptide-like immunoactivity in the accessory glands of male Helicoverpa armigera. J. Insect Physiol. 50: 241-248.

Picimbon J.F., Becard J.M., Sreng L., Clement J.L., Gadenne C. 1995. Juvenile hormone stimulates pheromonotropic brain factor release in the female black cutworm, Agrotis ipsilon. J. Insect Physiol. 41: 377-382.

Rafaeli A. 2001. Neuroendocrine control of pheromone biosynthesis in moths. Int. Rev. Cytol. 213: 49-92.

Raina A.K. 1989. Male-induced termination of sex pheromone production and receptivity in mated females of Heliothis zea. J. Insect Physiol. 35: 821-826.

Raina A.K., Werginb W.P., Murphylo C.A., Erbe E.F. 2000. Structural organization of the sex pheromone gland in Helicoverpa zea in relation to pheromone production and release. Arthropod Struct. Dev. 29: 343-353.

Ramaswamy S.B., Qiu Y., Park Y.I. 1996. Neuronal control of postcoital pheromone production in the moth Heliothis virescens. J. Exp. Zool. 274: 255-263.

Rice W.R. 1989. Analyzing tables of statistical tests. Evolution 43: 223-225.

Saudan P., Hauck K., Soller M., Choffat Y., Ottiger M., Sporri M., Zhaobing D., Hess D. 2002. Ductucs ejaculatorius peptide 99B (DUP99B), a novel Drosophila melanogaster sex peptide pheromone. Eur. J. Biochem. 269: 989-997.

Schägger H. 2006. Tricine-SDS-PAGE. Nat. Protoc. 1: 16-22.

Schmidt T., Choffat M., Schneider M., Hunziker P., Fuyama Y., Kubli E. 1993. Drosophila suzukii contains a peptide homologous to the Drosophila melanogaster sex-peptide and functional in both species. Insect Biochem. Mol. Biol. 23: 571579.

Scott D. 1987. The timing of the sperm effect on female Drosophila melanogaster receptivity. Anim. Behav. 35: 142-149.

Shobha A., Manjulakumari D., Bali G. 2009. An inexpensive technique for mass earing of pod borer, Helicoverpa armigera (Hubner). In Shakunthala S. et al. (eds.) Recent Trends in Animal Behaviour. New India Publishing Agency, New Delhi, pp. 209-219.

Simmons L.W. 2001. Sperm Competition and its Evolutionary Consequences in the Insects. Princeton University Press, Princeton.

Wolfner M.F. 1997. Tokens of Love: Functions and regulation of Drosophila male accessory gland products. Insect Biochem. Mol. Biol. 27: 179-192. 